Jurnal Teknik Komputer AMIK BSI

Volume 7, No.2, Juli 2021

P-ISSN 2442-2436, E-ISSN: 2550-0120

Akreditasi Ristekdikti, No: 36/E/KPT/2019 (Sinta 4)

DOI: $10.31294 /$ jtk.v4i2

\title{
Perancangan Sistem Informasi SDM Unit Kesehatan Berbasis Dekstop Pada Klinik Pratama Pusdikkes Kramat Jati
}

\author{
Khairul Rizal $^{1}$, Firstianty Wahyuhening Fibriany ${ }^{2}$, Ahmad Mustajib \\ ${ }^{1,2,3}$ Sistem Informasi Fakultas Teknologi Informasi \\ Universitas Bina Sarana Informatika \\ 1e-mail: khairul.krl@bsi.ac.id \\ ${ }^{2}$ e-mail: Firstianty.fbr@bsi.ac.id \\ 3e-mail: ahmadmustajib99@gmail.com
}

\begin{tabular}{ccc}
\hline Diterima & Direvisi & Disetujui \\
$18-06-2021$ & $04-07-2021$ & $21-07-2021$ \\
\hline
\end{tabular}

\begin{abstract}
Abstrak - Kemajuan teknologi disertai tingginya mobilitas kerja memberikan persaingan ketat di jaman modern saat ini, Pendataan pegawai mulai dari absensi pegawai, penilaian kinerja pegawai dan pendataan cuti atau ijin pegawai, secara tidak langsung membutuhan sistem yang sudah terkomputerasi. Sistem yang terkomputerisasi lebih baik dari sistem yang manual agar berjalan lebih efektif dan efisien serta sistem pendataan yang sekarang lebih kondusif dibandingkan dengan sistem manual. Klinik Pratama Pusdikkes salah satu klinik kesehatan yang berada di kramat Jati Jakarta yang sampai saat ini belum terkomputerisasi terutama Dalam mengelola data dokumen sumber daya manusia unit kesehatan sehingga memungkinkan pada saat proses berlangsung terjadi kesalahan dalam pendataan, kurang akuratnya laporan yang dibuat dan keterlambatan dalam pencarian data-data yang diperlukan. Media yang digunakan berupa kertas sehingga mengakibatkan data mudah hilang, rusak dan kotor, sehingga membutuhkan waktu yang cukup lama untuk membuat dan mengolah kembali data-data tersebut.
\end{abstract}

Kata Kunci : $\quad$ Sumber Daya Manusia, Kinerja Pegawai, Komputerisasi

\begin{abstract}
Technological advances accompanied by high work mobility provide tough competition in today's modern era. Employee data collection starting from employee attendance, employee performance appraisals and data collection on leave or employee permits, indirectly requires a computerized system. The computerized system is better than the manual system to run more effectively and efficiently and the data collection system is now more conducive than the manual system. Pratama Clinic Pusdikkes is one of the health clinics located in Kramat Jati, Jakarta which until now has not been computerized, especially in managing the human resource document data of the health unit so that it is possible during the process there are errors in data collection, inaccurate reports made and delays in data retrieval. -required data. The media used is in the form of paper so that data is easily lost, damaged and dirty, so it takes a long time to create and reprocess the data.
\end{abstract}

Keywords : Human Resources, Employee Performance, Computerization

\section{PENDAHULUAN}

Kemajuan teknologi disertai tingginya mobilitas kerja memberikan persaingan ketat di jaman modern saat ini, Perkembangan teknologi juga sangat berpengaruh pada kemajuan suatu organisasi. Teknologi memberikan sebuah kecepatan dan keakuratan dalam melakukan pengolahan data bila dibandingkan dengan cara manual. Dimana hal-hal yang manual dapat dibuat menjadi otomatisasi sehingga dapat mempermudah dalam mengelola data.

Perkembangan teknologi diperlukan Sumber Daya Manusia di Unit Kesehatan (SDMK) 2 yang terampil dapat juga menunjang pemanfaatan teknologi komputer yang ada. Dengan memanfaatkan teknologi komputer yang ada, maka akan membantu suatu sistem informasi penyimpanan data pegawai, penilaian kerja yang prosesnya dilakukan masih secara manual. Dimana suatu proses yang dilakukan secara manual akan mengalami banyak kendala misalnya dalam penyimpanan arsip, penyimpanan secara manual dengan data penting dan memakan waktu yang cukup lama yang mengakibadkan terlambatnya dalam penyelesaian laporan data pegawai kepada kepala klinik, dan juga absen, pengajuan cuti atau ijin yang masih menggunakan tulis tangan akan mengakibatkan tidak maksimalnya pengawasan pegawai yang dilakukan kepala klinik.

Sistem informasi yang mendukung agar mendapatkan hasil yang lebih maksimal dan membantu divisi SDM untuk bekerja lebih baik. Informasi mengenai sumber 
daya manusia sangatlah dibutuhkan oleh perusahaan guna menunjang kinerja sumber daya manusia dan juga kinerja perusahaan tersebut Pengajuan cuti dan absensi karyawan adalah beberapa kegiatan yang merupakan bagian dari HRM. Apabila suatu perusahaan menangani pengajuan cuti atau klaim secara lambat dan bertele-tele akan membuat karyawan menjadi tidak puas.(Wardhani \& Aziz, 2018)

Tuntutan pelayanan informasi dan pengelolaan informasi secara terintegrasi menjadi sangat penting di setiap lembaga, termasuk di suatu klinik. Klinik berdasarkan peraturan menteri kesehatan RI nomor 028/Menkes/Per/I/2011 adalah fasilitas pelayanan kesehatan yang menyelenggarakan pelayanan kesehatan perorangan yang menyediakan pelayanan medis dasar atau spesilalistik, diselenggarakan oleh lebih dari satu jenis tenaga kesehatan dan dipimpin oleh seorang tenaga medis. Dalam mengelola data sumber daya manusia unit kesehatan pada Klinik Pratama Pusdikkes Kramat Jati masih dilakukan secara manual, pengelolaan data sumber daya manusia unit kesehatan yang dimulai dari proses pendataan pegawai sumber daya manusia unit kesehatan, penginputan data pegawai, kontrak kerja pegawai, absensi kehadiran pegawai, penilain kinerja pegawai, hingga proses pemilahan data pegawai serta membuat pelaporan data sumber daya manusia unit kesehatan dan rekapitulasi laporan keseluruhan data sumber daya manusia unit kesehatan sehingga admin bisa melaporkan kebutuhan Pegawai ke Kepala Klinik Pratama Pusdikkes Kramat Jati.

Untuk pentingnya dilakukan penelitian ini, maka diuraikan penelitian yang sudah ada sebelumnya untuk dijadikan acuan dalam penelitian ini :

PT. Klik Teknologi Indonesia yang merupakan sebuah perusahaan yang bergerak di bidang teknologi. Manajemen SDM di PT. Klik Teknologi Indonesia belum ditunjang oleh teknologi sistem informasi. Sistem pengajuan cuti dan klaim masih dilakukan secara manual sehingga pengelolaannya belum optimal dan prosesnya kurang cepat. Seringkali terjadi ada pengajuan yang terlewat karena divisi SDM kewalahan dengan banyaknya pengajuan yang masuk. Kendala lain yang dihadapi oleh PT. Klik Teknologi Indonesia adalah masalah absensi, karyawankaryawan dari PT. Klik Teknologi Indonesia memiliki hak untuk bekerja secara remote atau bekerja diluar kantor, hal tersebut menyulitkan bagian SDM untuk mencatat data absensi. Mereka harus mencatat data dari kayawan yang bekerja secara remote dan mencocokkannya dengan data karyawan yang bekerja di kantor (Wardhani \& Aziz, 2018)

Strategi organisasi/perusahaan yang competitive akan dapat dirumuskan melalui berbagai masukan dari sumber daya manusia dan menjadi dasar dalam penyusunan perencanaan sumber daya manusia (human resources planning). Hal ini dapat diwujudkan melalui proses yang didukung instrumen kebijakan dengan melakukan analisis dan identifikasi kebutuhan sumber daya manusia serta ketersediannya. Tindakan dari proses tersebut melalui tahapan pemeriksaan audit sumber daya manusia, agar diperoleh dasar keputusan terhadap kondisi objektif atas berbagai permasalahan strategi dalam kebutuhan sumber daya manusia yang direncanakan. Naik turunnya kinerja perusahaan karena adanya beberapa faktor yang mempengaruhinya. Pada umumnya kinerja perusahaan yang optimal dipengaruhi oleh faktor internal maupun eksternal. Faktor internal yang diduga kuat memberikan pengaruh terhadap kinerja perusahaan saat ini salah satunya diantaranya karena Sistem informasi SDM yang juga berpengaruh terhadap Kinerja. Hal ini bisa disebabkan Sarana sistem informasi SDM yang kurang mendukung, dalam hal ini penerapan sistem informasi SDM yang akurat, relevan, lengkap dan tepat waktu. Di perusahaan, pemanfaatan Sistem Informasi Sumber Daya Manusia

(Human Resource Informastion Sistem) mampu meningkatkan kinerja dan daya saing bisnis ketika kebutuhan akan informasi yang cepat tepat dan ketersediaan data untuk proses pengambilan keputusan dibutuhkan.(Rusjiana, 2019)

Dari beberapa permasalahan yang diuraikan diatas, maka diperlukan sistem informasi manajemen SDM yang terkomputerisasi dengan adanya sistem informasi tersebut bisa dikembangkan membuat pengelolaan SDM yang di perusahaan menjadi lebih mudah, cepat dan akurat,dan dapat juga mengelola data pegawai dan laporan dari pegawai tersebut. Oleh karena itu penulis ingin permasalahan ini dijadikan penelitian sistem informasi yang terkomputerisasi.

\section{METODOLOGI PENELITIAN}

Untuk mendapatkan informasi yang diperlukan untuk penelitian, penulis melakukan riset pada Klinik Pratama Pusdikkes Kramat Jati, Jakarta dengan tujuan mengetahui alur manajemen SDM yang sedang berjalan, serta melihat kekukarangan dan kelemahan dalam alur tersebut. Berikut metode penelitian yang penulis gunakan, diantaranya :

\section{Teknik Pengumpulan Data}

Data yang diperoleh penulis saat melakukan riset di Klinik Pratama Pusdikkes Kramat Jati, Jakarta ada beberapa metode pengumpulan data antara lain :

\section{A. Observas}

Melakukan pengamatan yang khusus dan secara langsung di Klinik Pratama Pusdikkes Kramat Jati pada unit bagian administrasi (TUUD HRD) untuk mendapatkan data-data yang diperlukan serta untuk mengetahui permasalahan yang dihadapi.

B. Wawancara / Interview.

Memperoleh data dengan bertanya langsung kepada unit bagian admistrasi, bagian personalia yang berwenang terhadap SDM di Klinik Pratama Pusdikkes Kramat Jati. Pada metode ini sebelumnya penulis menyusun pertanyaanpertanyaan yang akan diajukan kepada petugas 
administrasi terlebih dahulu untuk mengumpulkan data mengenai sistem yang sedang dijalankan di Klinik Pratama Pusdikkes Kramat Jati.

C. Studi Pustaka

Metode ini untuk mendukung data yang telah didapat dari perusahaan dengan referensi dari buku-buku, jurnal cetak yang mengacu pada bidang yang berkaitan dengan penelitian ini.

\section{Model Pengembangan Sistem}

Metode penelitian yang digunakan untuk pengembangan sistem adalah metode waterfall. Metode waterfall digunakan karena mempermudah dalam melakukan pengembangan sistem karena harus melalui tahapan-tahan yang dilakukan(Abdurrahman \& Masripah, 2017)

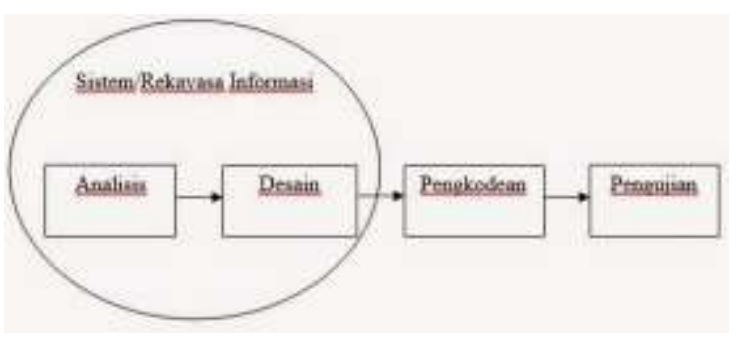

Gambar 1. Model Waterfall

Sumber : (Sukamto \& Salahudin, 2013)

Tahapan-tahapannya adalah sebagai berikut :

1. Analisis

Merupakan proses pengumpulan kebutuhan sistem informasi. Untuk memahami dasar dari program yang akan dibuat, seorang analisis harus mengetahui ruang lingkup informasi, fungsifungsi yang dibutuhkan, kemampuan kinerja yang ingin dihasilkan dan perancangan antarmuka pemakai sistem informasi tersebut. (Fahmi \& Ariani, 2018)

2. Desain

Desain perangkat lunak adalah proses multi langkah yang focus pada desain pembuatan program perangkat lunak termasuk struktur data, arsitektur perangkat lunak, representasi antarmuka, dan prosedur pengodean. Tahap ini mentranslasi kebutuhan perangkat lunak dari tahap analisis kebutuhan ke representasi desain agar dapat diimplementasikan menjadi program pada tahap selanjutnya.

3. Pengkodean

Pengkodean sistem informasi merupakan proses penulisan bahasa program agar sistem informasi tersebut dapat dijalankan oleh mesin (Fahmi \& Ariani, 2018)

4. Pengujian

Pengujian fokus pada perangkat lunak secara dari segi lojik dan fungsional dan memastikan bahwa semua bagian sudah diuji. Hal ini dilakukan untuk meminimalisir kesalahan (error) dan memastikan keluaran yang dihasilkan sesuai yang diinginkan.

\section{HASIL DAN PEMBAHASAN}

Dari hasil dari penelitian ini berupa implementasi dari model waterfaal, yang sudah dijelaskan sebelumnya di model pengembangan sistem.

1. Analisa Kebutuhan

Kebutuhan Pengguna :

Dalam aplikasi Sumber Daya Manusia Kesehatan (SDMK) ini terdapat dua pengguna yang dapat saling berinteraksi dalam lingkungan system, yaitu: Tata Usaha Urusan Dalam (TUUD/HRD) dan Pegawai. Kedua pengguna tersebut memiliki karakteristik interaksi dengan system yang berbeda-beda dan memiliki kebutuhan informasi yang berbeda-beda, seperti berikut :

A1. Skenario Kebutuhan TUUD/HRD

a) Mengelola Data Pegawai

b) Mengecek Absensi Pegawai

c) Membuat Kontrak Kerja Pegawai

d) Melakukan penilaian kinerjae)

e) Mengelola data cuti/ijin pegawai

f) Membuat laporan pegawai

g) Mengelola laporan absensi pegawai

h) Mengelola karir pegawai

A2. Skenario Kebutuhan Pegawai

a) Pegawai melakukan update profil data pegawai

b) Pegawai melakukan absensi

c) Pegawai melihat penilaian kinerja

d) Pegawai melihat karirnya

e) Pegawai melihat data jumlah cuti/ijin

Kebutuhan Sistem

B1. Admin

a) Admin melakukan login terlebih dahulu untuk masuk ke menu utama.

b) Menu utama admin terdiri dari menu master, transaksi, laporan, utility dan logout.

c) Menu Master master terdiri dari menu pegawai, menu jabatan, menu bagian, menu perijinan, dan menu penilaian kerja.

Menu Transaksi terdiri dari kontrak kerja, ijin atau cuti, kenaikan atau penurunan jabatan, penilaian pegawai.

d) Menu Laporan terdiri dari laporan pegawai, kontrak kerja, kenaikan jabatan, perijinan, ijin atau cuti dan penilaian.

e) Menu utility terdiri dari login dan ganti password.

f) Menu logout untuk keluar ke aplikasi. 
B2. User

a) User melakukan login untuk masuk ke menu utama user

b) Menu utama user terdiri dari transaksi,utility, logout

c) Menu transaksi terdiri dari menu ijin atau cuti dan menu absensi

d) Menu Utility bisa ganti password dan ubah profil data pegawai

e) Menu Logout untuk keluar ke aplikasi

B3. Pengguna harus melakukan login terlebih dahulu untuk dapat mengakses aplikasi ini dengan memasukkan username dan password agar privasi masing-masing pengguna tetap terjaga keamanannya.
B4. Pengguna harus melakukan logout setelah selesai menggunakan aplikasi.

B5. Sistem menerima data masukan dari pengguna dan mengelola data tersebut.

B6. Sistem melakukan laporan rekapan data pegawai

2. Desain

Untuk memberikan gambaran yang jelas tentang sistem yang dibangun dibutuhkan rancangan sistem informasi, rancangan database, antar muka untuk memudahkan dalam proses implementasi sistem.

A. Use case diagram

Pada perancangan sistem informasi sumber daya manusia unit kesehatan berbasis dekstop digambarkan use case diagram login

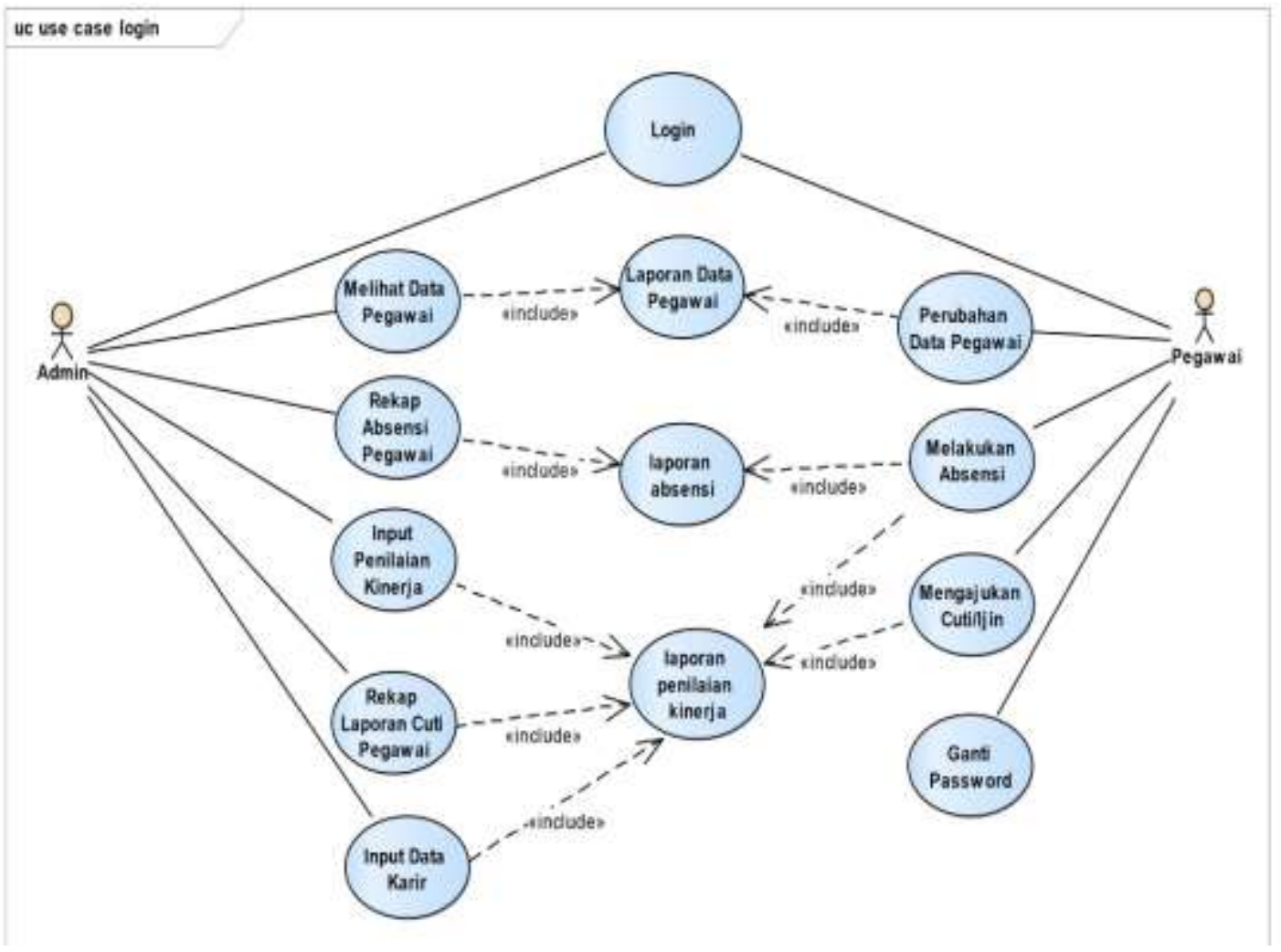

Gambar 2. Use Case Diagram Login

B. Activity Diagram

Pada perancangan sistem informasi sumber daya manusia unit kesehatan berbasis dekstop digambarkan Activity Diagram hubungan antara administrasi dan pegawai 


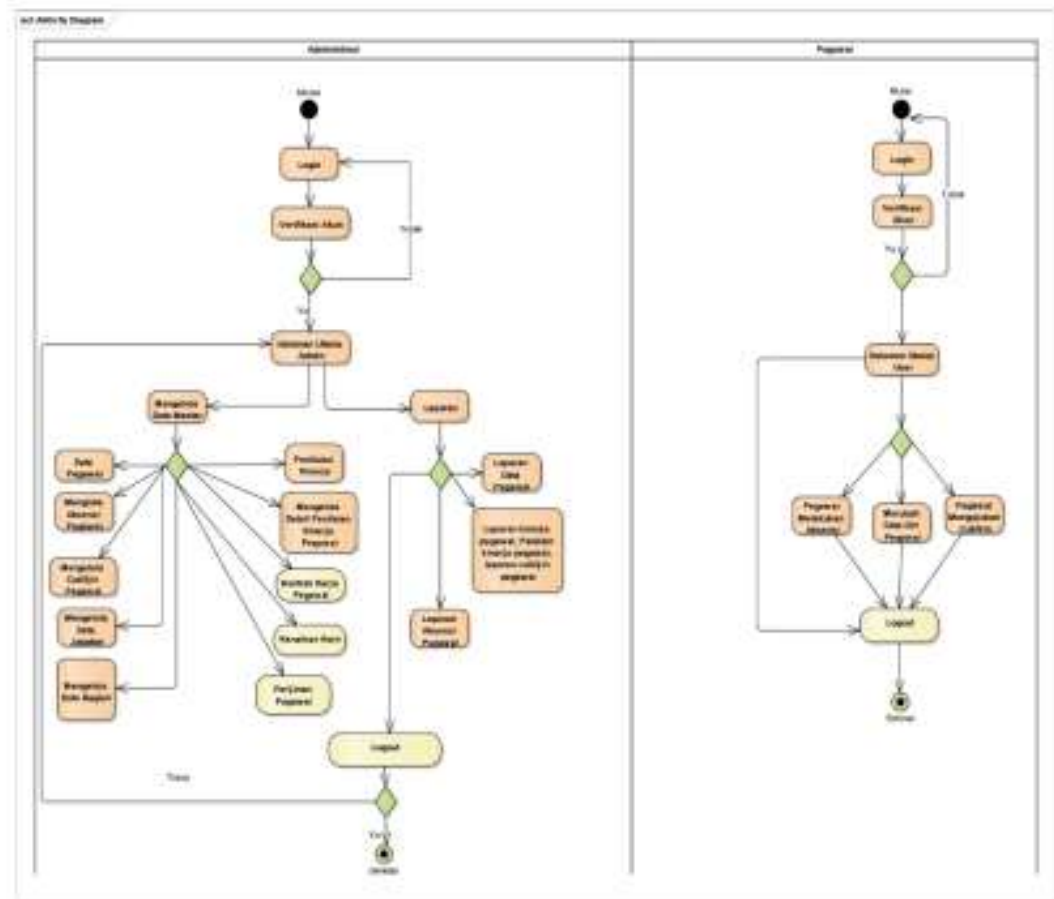

Gambar 3. Activity Diagram

C. Rancangan Database

Dibutuhkan database untuk menyimpan data dari suatu aplikasi. Pada sistem informasi sumber daya manusia, database yang digunakan adalah
MySql, dan perancangan basis data menghasilkan pemetaan tabel-tabel yang digambarkan menggunakan Entity Relationship Diagram (ERD), berikut desainnya :

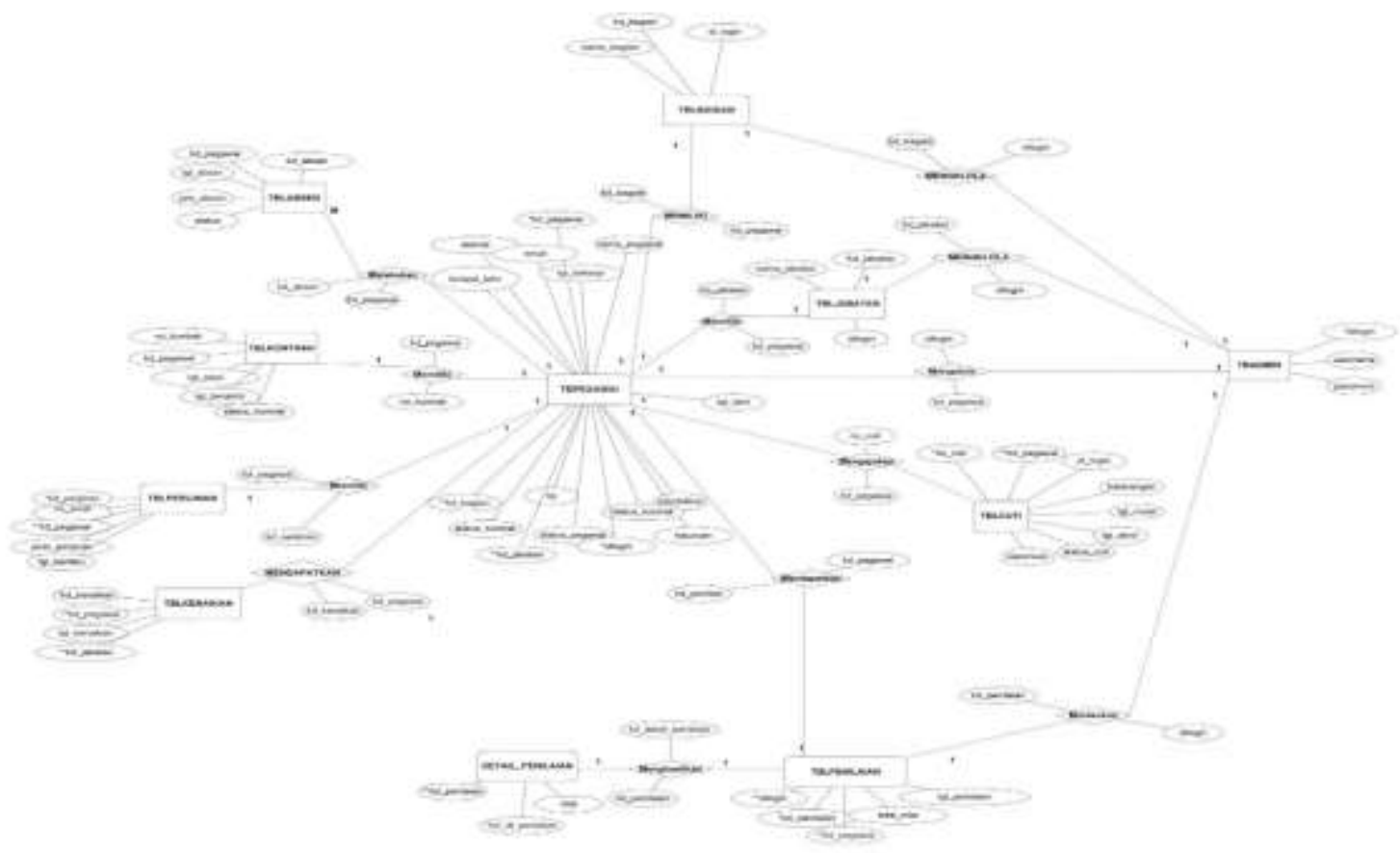

Gambar 4.ERD SDM Unit Kesehatan 
D. Rancangan Antar Muka

Berikut ini beberapa tampilan desain antar muka dari sistem informasi SDM unit Kesehatan yang dibuat

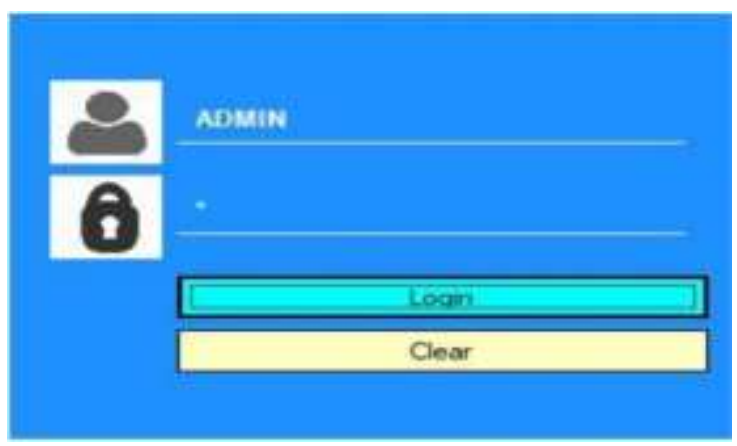

Gambar 5.Login Admin

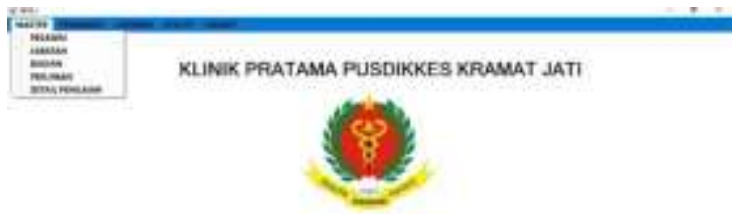

$\min _{i=1}$

Gambar 6. Menu Utama Master
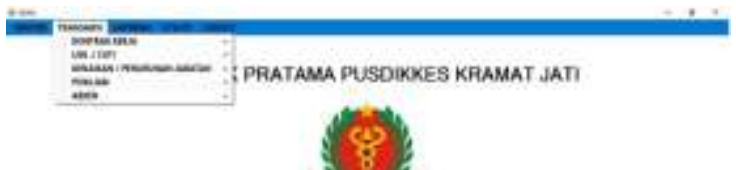

$+1 \rightarrow \infty$

Gambar 7. Menu Utama Transaksi
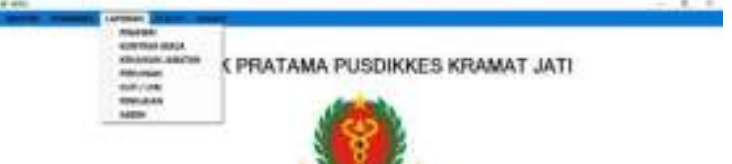

nower

Gambar 8. Menu Utama Laporan

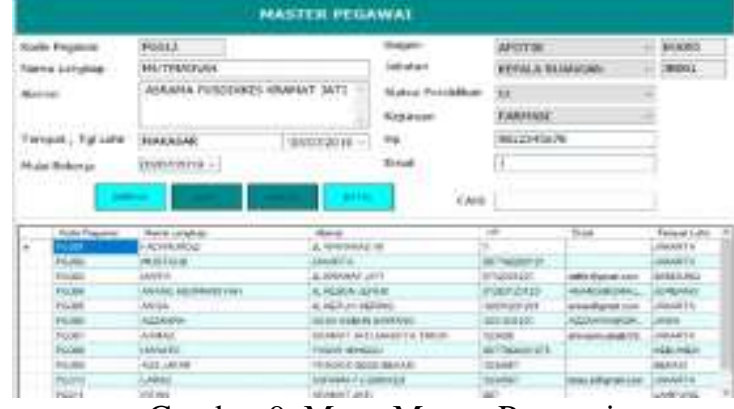

Gambar 9. Menu Master Pegawai

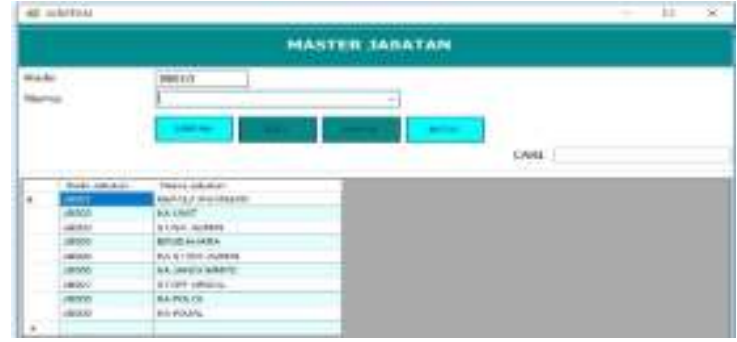

Gambar 10. Menu Master Jabatan

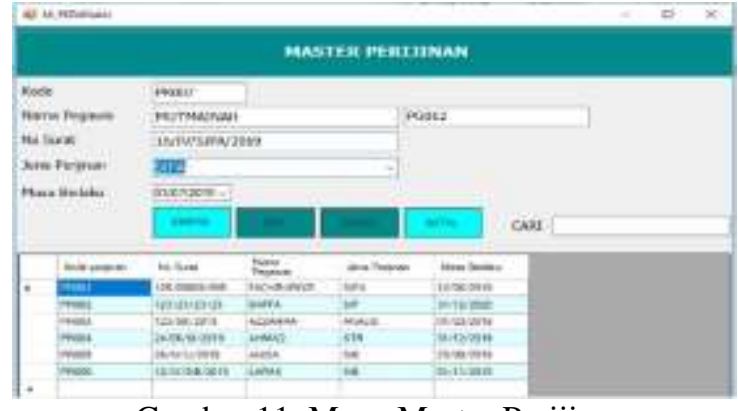

Gambar 11. Menu Master Perijinan

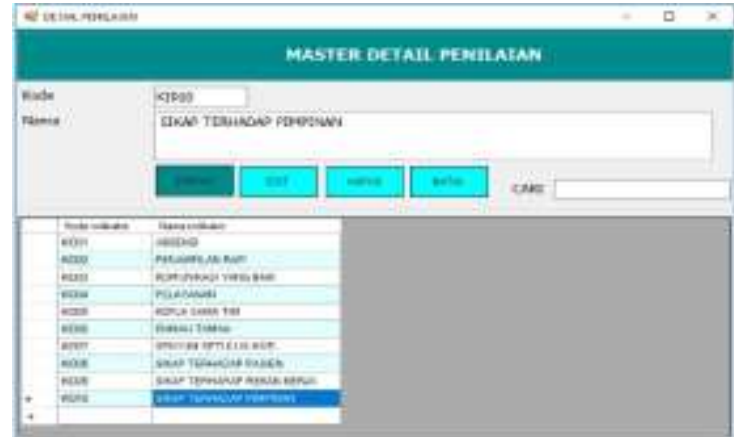

Gambar 12. Menu Master Indikator

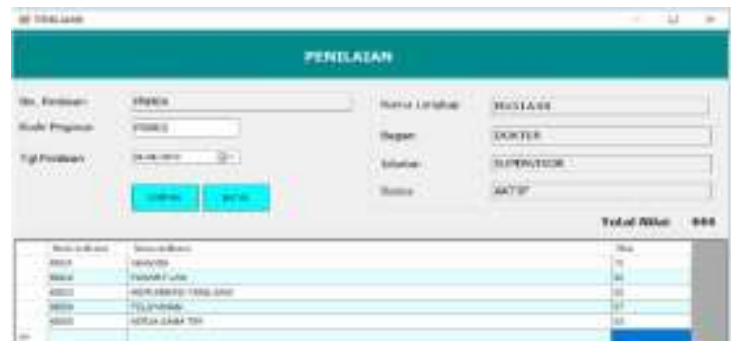

Gambar 13. Menu Penilaian Kerja 


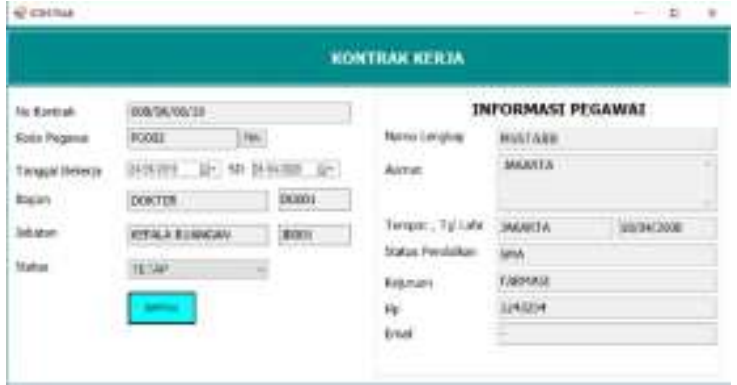

Gambar 14. Menu Kontrak Kerja

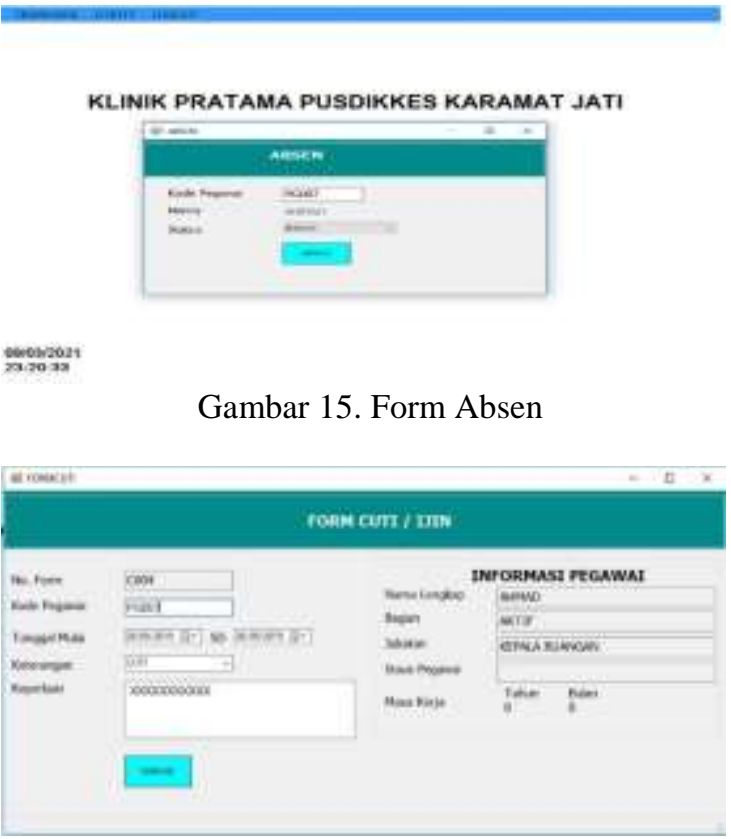

Gambar 16. Form Cuti atau Ijin

3. Pengkodean

Langkah selanjutnya adalah pengkodean atau coding, Penerapan sistem informasi manajemen SDM unit kesehatan ini menggunakan aplikasi visual basic sebagai rancangan programnya. Aplikasi dirancang

berbasis dekstop untuk mempermudah pengguna dalam menggunakan sistem informasi manajemen SDM unit kesehatan ini.

4. Pengujian

Untuk tahap pengujian atau testing, penulis menggunakan pengujian denganmetode blackbox, dimana pengujiannya dilakukan pada tampilan program apakah program dapat berjalan dengan baik sesuai yang diinginkan.

Tabel 1. Form Login

\begin{tabular}{lllll}
\hline \multirow{2}{*}{ No } & $\begin{array}{l}\text { Skenario } \\
\text { Uji }\end{array}$ & $\begin{array}{l}\text { Hasil yang } \\
\text { diharapkan }\end{array}$ & $\begin{array}{l}\text { Hasil } \\
\text { Pengujian }\end{array}$ & $\begin{array}{l}\text { Kesimpul } \\
\text { an }\end{array}$ \\
\hline 1 & Mengoso & Sistem akan & Sesuai & Valid \\
& ngkan & menolak & harapan & \\
& username & akses user & & \\
& dan & dan & & \\
& password & menampilk & & \\
& dan & an "Login & & \\
& langsung & Gagal, & & \\
\hline
\end{tabular}

\begin{tabular}{|c|c|c|c|c|}
\hline & $\begin{array}{l}\text { menekan } \\
\text { Tombol } \\
\text { Log In }\end{array}$ & $\begin{array}{l}\text { mohon cek } \\
\text { username } \\
\text { dan } \\
\text { password } \\
\text { Anda }\end{array}$ & & \\
\hline 2 & $\begin{array}{l}\text { Mengisi } \\
\text { username } \\
\text { dan } \\
\text { password } \\
\text { dengan } \\
\text { salah dan } \\
\text { menekan } \\
\text { Tombol } \\
\text { Log In }\end{array}$ & $\begin{array}{l}\text { Sistem akan } \\
\text { menolak } \\
\text { akses user } \\
\text { dan } \\
\text { menampilk } \\
\text { an "Login } \\
\text { Gagal, } \\
\text { mohon cek } \\
\text { username } \\
\text { dan } \\
\text { password } \\
\text { Anda }\end{array}$ & $\begin{array}{l}\text { Sesuai } \\
\text { harapan }\end{array}$ & Valid \\
\hline 3 & $\begin{array}{l}\text { Mengisi } \\
\text { username } \\
\text { dan } \\
\text { password } \\
\text { dengan } \\
\text { benar dan } \\
\text { menekan } \\
\text { Tombol } \\
\text { Log In }\end{array}$ & $\begin{array}{l}\text { Sistem akan } \\
\text { masuk dan } \\
\text { akses ke } \\
\text { menu } \\
\text { utama } \\
\text { dengan user } \\
\text { yang login } \\
\text { serta } \\
\text { menampilk } \\
\text { an login } \\
\text { berhasil }\end{array}$ & $\begin{array}{l}\text { Sesuai } \\
\text { harapan }\end{array}$ & Valid \\
\hline
\end{tabular}

Sumber : (Rizal et al,. 2021)

Tabel 2. Form Login

\begin{tabular}{|c|c|c|c|c|}
\hline No & $\begin{array}{l}\text { Skenario } \\
\text { Uji }\end{array}$ & $\begin{array}{l}\text { Hasil yang } \\
\text { diharapkan }\end{array}$ & $\begin{array}{l}\text { Hasil } \\
\text { Pengujian }\end{array}$ & $\begin{array}{l}\text { Kesimpul } \\
\text { an }\end{array}$ \\
\hline 1 & $\begin{array}{l}\text { User } \\
\text { menamba } \\
\text { h data } \\
\text { pegawai } \\
\text { dengan } \\
\text { mengisi } \\
\text { data } \\
\text { master } \\
\text { pegawai } \\
\text { dari kode } \\
\text { pegawai } \\
\text { sampai } \\
\text { email }\end{array}$ & $\begin{array}{l}\text { Data yang } \\
\text { telah } \\
\text { diinput ke } \\
\text { dalam } \\
\text { textbox } \\
\text { bisa masuk } \\
\text { ke dalam } \\
\text { database } \\
\text { dan muncul } \\
\text { di halaman } \\
\text { utama } \\
\text { Menu } \\
\text { Master } \\
\text { Pegawai } \\
\end{array}$ & $\begin{array}{l}\text { Sesuai } \\
\text { harapan }\end{array}$ & Valid \\
\hline 2 & $\begin{array}{l}\text { User } \\
\text { Mengedit } \\
\text { data } \\
\text { pegawai }\end{array}$ & $\begin{array}{l}\text { Data yang } \\
\text { ingin diedit } \\
\text { berhasil } \\
\text { di rubah } \\
\text { dari } \\
\text { tabel }\end{array}$ & $\begin{array}{l}\text { Sesuai } \\
\text { harapan }\end{array}$ & Valid \\
\hline 3 & $\begin{array}{l}\text { User } \\
\text { Menghap } \\
\text { us data } \\
\text { pegawai }\end{array}$ & $\begin{array}{l}\text { Data yang } \\
\text { ingin } \\
\text { dihapus } \\
\text { berhasil } \\
\text { di dihapus } \\
\text { dari } \\
\text { tabel }\end{array}$ & $\begin{array}{l}\text { Sesuai } \\
\text { harapan }\end{array}$ & Valid \\
\hline
\end{tabular}

Sumber : (Rizal et al,. 2021) 
Tabel 3. Form Master Perizinan

\begin{tabular}{|c|c|c|c|c|}
\hline No & $\begin{array}{l}\text { Skenario } \\
\text { Uji }\end{array}$ & $\begin{array}{l}\text { Hasil yang } \\
\text { diharapkan }\end{array}$ & $\begin{array}{l}\text { Hasil } \\
\text { Pengujian }\end{array}$ & $\begin{array}{l}\text { Kesimpul } \\
\text { an }\end{array}$ \\
\hline 1 & $\begin{array}{l}\text { User } \\
\text { menamba } \\
\mathrm{h} \\
\text { perijinan } \\
\text { data } \\
\text { pegawai } \\
\text { yang } \\
\text { ingin } \\
\text { melakuka } \\
\text { n ijin } \\
\text { sesuai } \\
\text { jenis } \\
\text { perijinan }\end{array}$ & $\begin{array}{l}\text { Data yang } \\
\text { telah } \\
\text { diinput ke } \\
\text { dalam } \\
\text { textbox } \\
\text { bisa masuk } \\
\text { ke dalam } \\
\text { database } \\
\text { dan muncul } \\
\text { di form } \\
\text { perijnan }\end{array}$ & $\begin{array}{l}\text { Sesuai } \\
\text { harapan }\end{array}$ & Valid \\
\hline 2 & $\begin{array}{l}\text { User } \\
\text { Mengedit } \\
\text { data } \\
\text { perijinan } \\
\text { pegawai }\end{array}$ & $\begin{array}{l}\text { Data yang } \\
\text { ingin diedit } \\
\text { berhasil } \\
\text { di rubah } \\
\text { dari } \\
\text { tabel }\end{array}$ & $\begin{array}{l}\text { Sesuai } \\
\text { harapan }\end{array}$ & Valid \\
\hline 3 & $\begin{array}{l}\text { User } \\
\text { Menghap } \\
\text { us data } \\
\text { perijinan } \\
\text { pegawai }\end{array}$ & $\begin{array}{l}\text { Data yang } \\
\text { ingin } \\
\text { dihapus } \\
\text { berhasil } \\
\text { di dihapus } \\
\text { dari } \\
\text { tabel }\end{array}$ & $\begin{array}{l}\text { Sesuai } \\
\text { harapan }\end{array}$ & Valid \\
\hline
\end{tabular}

Sumber : (Rizal et al,. 2021)

\section{KESIMPULAN}

Berdasarkan hasil penelitian yang telah dilakukan, maka dapat disimpulkan bahwa perancangan sistem informasi manajemen SDM unit kesehatan yang telah terkomputerisasi bisa mengatasi kendala terlambatnya penyampaian laporan dikarenakan banyaknya pekerjaan yang dilakukan dengan manual. Adanya sistem informasi manajemen SDM unit kesehatan yang telah terkomputerisasi akan mempermudah segala aktifitas pegawai di lingkungan klinik tersebut dan kesalahan-kesalahan yang terjadi dengan menggunakan sistem yang masih manual dapat diminimalkan, sistem yang sudah terkomputerisasi mampu menghasilkan informasi atau keluaran seperti kontak kerja dan penilaian kerja yang lebih tepat dan akurat, seperti halnya memudahahkan kepala klnik unutk memantau pegawai melakukan cuti atau ijin

\section{REFERENSI}

Abdurrahman, A., \& Masripah, S. (2017). Metode Waterfall Untuk Sistem Informasi Penjualan. Information System for Educators and Professionals, 2(1), 95 - 104.

Fahmi, M., \& Ariani, F. (2018). Rancang Bangun Sistem Informasi Akademik Berbasis Web Dengan Metode Waterfall. Jurnal LINK, 2(1), 119-124.

Rosa Ariani Sukamto, \& Salahudin, M. (2013). Rekayasa Perangkat Lunak Terstruktur dan Berorientasi Objek. Bandung.

Rusjiana, J. (2019). Pengaruh Sistem Informasi SDM Terhadap Kinerja Karyawan Di PT Rabbani Bandung. Jurnal Computech \& Bisnis, 10(1), 21-29.

Wardhani, N. K., \& Aziz, M. T. A. (2018). Sistem Informasi Manajemen Sumber Daya Manusia Berbasis Web ( Studi Kasus: Pt . Klik Teknologi Indonesia ). Jurnal TECHNO Nusa Mandiri, 15(2), 145-152. Retrieved from https://ejournal.nusamandiri.ac.id/index.php/te chno/article/view/24 